\title{
DESENVOLVIMENTO DA CONSCIÊNCIA AMBIENTAL NA EDUCAÇÃO INFANTIL
}

\author{
Larissa Costa Marvila ${ }^{1}$ \\ Désirée Gonçalves Raggi ${ }^{2}$
}

Resumo: Pesquisou-se sobre a horta utilizada como recurso didático para proporcionar o desenvolvimento da consciência ambiental, na Educação Infantil. Consistiu em aulas práticas para implementação de uma horta escolar, contando com a participação ativa das crianças em todas as etapas, que foram estimuladas a assumir responsabilidade e praticar cuidados diários com 0 plantio, cultivo e colheita dos alimentos produzidos. Para tanto buscou-se conciliar os conhecimentos prévios e os adquiridos nas aulas práticas. Nesse sentido, houve a intenção de desenvolver a consciência ambiental na formação dos educandos e de sensibilizar as crianças.

Palavras-chave: Educação Ambiental; Educação Infantil; Consciência Ambiental.

\footnotetext{
1 Faculdade Vale do Cricaré. E-mail: larissa.costa.marvila@gmail.com

2 Universidad del Norte. E-mail: desireeraggi@yahoo.com.br
} 


\section{Introdução}

A Educação Ambiental (EA) surge como um processo educativo, cujos saberes ultrapassam os conteúdos técnicos e científicos e se pautam na formação do ser humano completo. Assim, está engajada no desenvolvimento de valores éticos e de regras políticas, que compreendem as relações sociais e econômicas, que incidem sobre questões acerca da distribuição entre os benefícios e prejuízos da apropriação e do uso dos recursos naturais.

Portanto, deve estar voltada para a cidadania ativa considerando seu sentido de pertencimento e responsabilidade que, por meio da ação organizada e coletiva, busca compreender e superar as causas das estruturas e dos conjuntos de problemas ambientais (SORRENTINO, 2005). Dessa maneira, é imprescindível que a EA seja inserida no espaço de ensino, pois a escola tem como função conscientizar acerca dos efeitos das ações humanas sobre a natureza.

É considerável que o exercício da Educação Ambiental se dê em estreita relação com as questões ambientais locais, isto é, as ações pedagógicas devem tomar como ponto de partida os problemas ambientais que afetam a comunidade em questão. A EA pode fortalecer o poder das populações, dandoIhes instrumentos para planejar, gerenciar e implementar suas próprias alternativas consonantes com as políticas sociais vigentes, além de resgatar e propor soluções para a melhoria das condições de vida e o desenvolvimento de relações mais solidárias e afetivas entre os humanos, além de abordar os recursos naturais e o equilíbrio dos ecossistemas.

Como professora, a responsabilidade social, a ética e a política são atribuições inerentes à função docente, mas, muito além, disso, trata-se de se ver como cidadão de um município, de um estado, de um país, de um mundo, pelo qual todos são responsáveis pela preservação do meio ambiente e, consequentemente, pelo bem viver de toda uma população.

\section{Desenvolvimento}

Discutir a questão da consciência ambiental em crianças tão pequenas é preciso considerar que nesta idade elas ainda não são capazes de assimilar e refletir sobre conceitos e que a consciência se desenvolve pela compreensão de princípios éticos, aceitos pela comunidade em que se vive. Também não são dotadas de pensamento crítico para reconhecer o que é correto ou incorreto, para seu grupo social. É importante considerar que a construção cognitiva das crianças se consolida a partir dos exemplos e modelos observados.

De acordo com a teoria piagetiana, as crianças pequenas são sensóriomotoras não apenas do ponto de vista intelectual. São sensório-motoras em sua natureza integral, pois é através do movimento de seu corpo com o das sensações provocadas por sua relação com o mundo humano e com a 
natureza que elas assimilam hábitos e comportamentos e, constroem também referências afetivas e sociais (TIRIBA, 2010, p. 23).

Na medida em que vão praticando hábitos saudáveis e ecologicamente corretos, vão aprendendo as regras ambientais socialmente aceitas pelos grupos a que pertencem. Assim pode-se considerar que a consciência ambiental vai se constituindo pelas atitudes, hábitos e comportamentos voltados que são praticados no dia a dia, nos diversos espaços sociais.

[...] uma consciência ambiental implica na busca e na consolidação de novos valores na forma de ver e viver no mundo, a partir da complexidade ambiental, que possibilita a construção de novos padrões cognitivos na relação homem/natureza, ou seja, na produção de processos cognitivos que reconheçam a interdependência e o inacabamento de qualquer ação, de (des)construir e (re)construir o pensamento a partir da ciência, da cultura e da tecnologia, a fim de mover o processo criativo humano (Leff, 2001 apud SOARES, NAVARRO E FEREIRA)

As orientações da legislação apontam para a compreensão de que a Educação Ambiental se consolida sobre bases éticas e considera os valores humanos e sociais. Um dos principais pilares da EA indica que deve estar intimamente relacionada com as práticas reais da vida da comunidade, que são aplicadas para se conduzir a melhoria da qualidade ambiental, promovendo o desenvolvimento de conhecimentos, atitudes, habilidades e comportamentos.

Não se pode atribuir à $E A$ e às instituições educacionais a responsabilidade de resolver os problemas do mundo, problemas os quais, os próprios seres humanos provocam, de acordo com o estilo de vida que adotam para seu bem estar e sobrevivência. Contudo, é preciso acreditar que a escola seja um veículo envolvido na busca de possíveis soluções. Nesse sentido, propõe-se um projeto de EA que tenha início nos primeiros anos da Educação Infantil e que coloque as crianças em contato com a natureza, estimulando as sensações e os sentidos, ao tocar as sementes, as plantas, sentir o cheiro do solo, e interagir na troca de informações com os colegas.

$\mathrm{Na}$ medida em que as questões ambientais se tornam cada vez mais abrangentes e presentes, amplia-se a importância de consolidar saberes voltados para a compreensão desta problemática. A EA vem assumindo, nos últimos anos, uma importância cada vez maior diante da crise ambiental provocada pelas regras da sociedade capitalista, cujo crescimento está fortemente pautado no consumo de bens descartáveis e na produção de alimentos não seguros. Nesse sentido, constitui-se em um campo de estudos que se estabelece entre as diversas áreas de conhecimento e disciplinas que compõem o currículo escolar. 
Nessa perspectiva, a Educação Infantil assume importância sine qua non, pois de acordo com Oliveira (2012), a educação da primeira infância deve seguir os preceitos das Diretrizes Curriculares Nacionais (2010), bem como, as orientações sobre os conteúdos apresentados pela BNCC (2017). Neste cenário, as crianças da Educação Infantil devem ter acesso às problemáticas do atual contexto, como as questões relativas às diversidades, o respeito ao meio ambiente, a preocupação com a qualidade de vida, dentre outras, as quais tem contribuído para comportamentos individualistas, excludentes e consumistas. Nesse sentido, acrescenta a autora

[...] na Educação Infantil é fundamental que os conteúdos e práticas desenvolvidas levam as crianças a se reconhecerem como cidadãos ativos e cidadãos desde o nascimento. Que as práticas sejam centradas nas crianças levando em consideração cidadãos de direitos, que fujam de práticas assistencialistas e compensatórias, que realmente ensinem para esta etapa da Educação Básica (OLIVEIRA, 2012, p. 37).

A visão da articulista resgata a função pedagógica desta etapa de ensino e antagoniza com a ideia de programas alternativos para a Educação Infantil. As Diretrizes Curriculares Nacionais para a Educação Infantil (DCNEI, 2010), apregoam que as crianças pequenas podem e devem aprender a respeitar novas formas de vida, o cuidado com os seres vivos e a preservação do meio ambiente.

As diretrizes apontam três princípios para as propostas pedagógicas de Educação Infantil. São eles:

Éticos: da autonomia, da responsabilidade, da solidariedade e do respeito ao bem comum, ao meio ambiente e às diferentes culturas, identidades e singularidades.

Políticos: dos direitos de cidadania, do exercício da criticidade e do respeito à ordem democrática.

Estéticos: da sensibilidade, da criatividade, da ludicidade e da liberdade de expressão nas diferentes manifestações artísticas e culturais (BRASIL, 2010). 
Nota-se que quando os educadores adotam metodologias apropriadas, possibilitam o despertar do senso de solidariedade, pois nesse processo ocorre divisão de tarefas e partilha de conhecimentos. É válido ressaltar que além de desenvolver o respeito aos recursos naturais, ao manipular a terra, as plantas, a água e observar outros organismos presentes no meio, as crianças aprendem a respeitar e amar os seres vivos. E assim, vão se conscientizando sobre a necessidade de preservar e cuidar da natureza.

Algumas práticas pedagógicas favorecem a aprendizagem de valores como percepção e conhecimento e respeito para com as diferenças individuais e as singularidades dos colegas. Nesse sentido, o Parecer no 20/2009 sinaliza que as crianças podem e devem aprender sobre o valor de cada pessoa, de grupos sociais e culturais distintos, respeito à liberdade e integridades dos indivíduos e essa "[...] valorização também se estende à relação com a natureza e os espaços públicos, o respeito a todas as formas de vida, o cuidado de seres vivos e a preservação dos recursos naturais" (BRASIL, 2009).

As propostas pedagógicas para o exercício da Educação Ambiental na Educação Infantil, podem gerar mudanças de pensamentos e transformação de valores e atitudes que serão de grande importância para promover uma nova postura diante do meio em que se vive. A Educação Ambiental propõe a noção de responsabilidade não somente com 0 mundo e com a sociedade, mas também consigo próprio.

Sabe-se que é na Educação Infantil que ocorre o desenvolvimento moral e intelectual da criança perante a sua vida social, ambiental e cultural. De acordo com as palavras de Tiriba (2010, p. 2):

Creches e pré-escolas são espaços privilegiados para aprender-ensinar porque aqui as crianças colhem suas primeiras sensações, suas primeiras impressões do viver. Neste sentido, a dimensão ambiental não poderia estar ausente, ou a serviço da dimensão cultural, ambas deveriam estar absolutamente acopladas.

Tiriba (2010) brilhantemente apresenta questionamentos sobre o trabalho ofertado e desenvolvido junto às crianças da Educação Infantil, como: Quem são as crianças que atendemos? Como vivem? A autora salienta que a preocupação com nomenclaturas relativas às escolas de crianças pequenas é menos importante. O fundamental agora é refletir sobre o que se está fazendo com essas crianças.

O que se tem visto, conforme explicita ela, é um desenvolvimento racional junto às crianças. É muito acentuado o privilégio do conhecimento, do saber pensar, desvinculado do saber viver, do conviver, do viver juntos. Para ela, o contexto atual exige que se repense sobre as necessidades dessas 
crianças, pois as funções reservadas ao atendimento delas são altamente complexas e exigentes.

Discute-se sempre o posicionamento contra qualquer tipo de assistencialismo, especialmente sendo contra, de fato, mas assistir as crianças nessa etapa da vida supõe assumir funções maternas, paternas humanizadoras, pedagógicas de qualidade e excelência no sentido do que se está fazendo.

Tiriba (2010) questiona a falta de envolvimento das crianças com o meio natural. Elas crescem às vezes sem nunca conhecer o espaço, sem ter contato com este mundo. Para ela, adultos esquecem que a "[...] vida é colorida, utilizamos toquinhos de madeira para ensinar as cores às crianças ao invés de levá-las a sentir o céu, as árvores, a terra".

Piaget (1983) que muito contribuiu com pesquisas sobre 0 desenvolvimento humano, revela que é na idade infantil que ocorre o desenvolvimento moral e intelectual da espécie humana, e que esse se consolida em meio à vivência social, ambiental e cultural.

Piaget (1983, p. 257) dividiu os períodos do desenvolvimento humano de acordo com as novas qualidades do pensamento:

1ํ Período - sensório Motor, (0 a 2 anos); 2ํㅗ́odo - PréOperatório (2 a 7 anos); 3ํPeríodo - Operações Concretas (7 a 11 ou 12 anos); 4ํ Período- Operações Formais (11 ou 12 em diante).

Segundo esse pensador, cada período é caracterizado por aquilo que de melhor o indivíduo consegue fazer nessas faixas etárias. Para ele, todos os sujeitos passam por todas essas fases ou períodos, nessa sequência, e em cada período a criança é um ser que pensa, age, realiza. Nessa dimensão, a EA na Educação Infantil deve iniciar o processo de formação de cidadãos, sendo possível compreender o seu estar no mundo, as relações em sociedade e sua interação no mundo.

Não se pode afirmar que apenas o que foi aprendido no ambiente escolar vá fazer a diferença para aprimorar o mundo social e as condições de vida das populações humanas, pois a mudança requer contínuas e repetidas ações na fase infantil. Sendo assim, se fazem necessários o fortalecimento e os reforços positivos de atitudes em outros ambientes de convívio, principalmente, o familiar. Contudo, pode-se destacar - e isso é inegável em toda a formação do indivíduo - que na escola e na família, é que se dá o ponto de partida para o processo de formação dos sujeitos. Cabe, então, à escola e à família modificar hábitos a fim de que haja melhorias contínuas com relação à inter-relação dessa criança com o meio ambiente. 
Para abordar conteúdos referentes ao meio ambiente na Educação Infantil, percebe-se que é necessário mais do que informações e conceitos. Os educadores devem selecionar conteúdos e estratégias pedagógicas apropriadas como meios capazes de proporcionar a construção de atitudes e a formação de valores éticos e moralmente aceitos. Importante destacar que, nesta etapa de desenvolvimento, deve se assegurar a introdução da temática ambiental de forma interdisciplinar, nos currículos de todas as disciplinas e em atividades escolares, que busquem o interesse dos alunos. No entanto, essas devem ocorrer em um ambiente descontraído, onde os professores possam explorar ao máximo o contato com os objetos da natureza (solo, água, vegetais, dentre outros). Conforme indicam os fundamentos de Piaget (1983), os professores devem garantir a relação entre a criança e o meio ambiente.

Nesse sentido, Penteado (2009, p. 16) contribui ao assinalar a importância da educação formal, afirmando que a escola

[...] é, sem sombra de dúvida, o local ideal para se promover este processo. As disciplinas escolares são os recursos didáticos através dos quais os conhecimentos científicos de que a sociedade já dispõe são colocados ao alcance dos alunos. As aulas são o espaço ideal de trabalho com os conhecimentos e onde se desencadeiam experiências e vivências formadoras de consciências mais vigorosas porque alimentadas no saber.

Compreende-se assim, a importância do trabalho do docente em introduzir a questão ambiental na prática pedagógica, sendo a mesma um referencial para as crianças de como descobrir respostas e encontrar soluções para os problemas envolvidos nessa temática.

Piaget (1983), diz que a criança não é um ser em miniatura, e que no período pré-operatório ( 2 aos 7 anos) o evento mais importante é o aparecimento da linguagem, e é esta que permite avanços. Há, nesse período, a maturação neurofisiológica, o que permite o desenvolvimento de novas habilidades.

Por meio da curiosidade e da necessidade em explorar o meio, é que as crianças se integram a ele. Dessa forma, as aulas na Educação Infantil precisam deixar o senso comum e começar, pela prática, a estimular as crianças a descobrirem os problemas ambientais que afetam a sociedade. As atividades ao ar livre proporcionam aos educandos aprendizagens que trazem bem-estar ao serem realizadas, aflorando os sentimentos de solidariedade e companheirismo, deixando um pouco de lado atividades individualistas e competitivas, constituindo assim um espaço de convivência. 


\section{Metodologia}

Trata-se de uma pesquisa de caráter qualitativo e descritivo, pois descreve como uma professora implantou uma horta escolar para desenvolver hábitos e comportamentos para o desenvolvimento da consciência ambiental em crianças de 3 e 4 anos. É exploratória porque explora e analisa como essas atividades desenvolvidas durante os cuidados práticos na horta contribuíram para que as crianças aprendessem e se habituassem a cuidar da natureza, considerando os pressupostos de Moreira e Caleffe (2008, p. 73).

É também uma pesquisa-intervenção que viabiliza a construção de espaços de problematização coletiva junto às práticas de formação e potencializa a produção de um novo pensar/fazer educação (ROCHA; AGUIAR, 2003). A pesquisa-intervenção é uma modalidade de investigação que se contrapõe ao modelo tradicional/positivista, a qual defende a neutralidade do investigador. No percurso metodológico deste estudo, se entrelaçaram os momentos de intervenção promovidos pela educadora/pesquisadora com os momentos de observação da própria prática e, em seguida, com os momentos de reflexão/análise para a sistematização da escrita dos resultados obtidos, quando atuou na qualidade de pesquisadora.

\section{Resultados e discussões}

Com base nas informações coletadas e nos momentos vivenciados ao longo do processo da pesquisa, observou-se que a horta escolar proporciona práticas vivenciais que são, de forma irrefutável, a melhor maneira de se apropriar das teorias e conceitos da EA, trazendo para a prática diversos saberes e fundamentos que os educandos só viam no espaço interno da sala de aula. e passaram a ver de forma concreta, na rotina diária de cuidados com a horta escolar e os frutos que ela gerou.

Dessa forma, a concepção pedagógica envolve a prática da horta escolar que se forma no diálogo entre os indivíduos envolvidos no processo e tem como objetivo construir um projeto pedagógico interdisciplinar. Também tem como meta transformar a horta escolar num "laboratório de aprendizagem" no Centro de Educação Infantil, interligando os saberes com os sujeitos e sua identidade.

\section{Considerações finais}

A horta utilizada como recurso didático para desenvolver a consciência ambiental foi inserida no cotidiano escolar na Educação Infantil por meio de atividades, incorporando as práticas nas atividades pedagógicas no processo de ensino-aprendizagem, ao resgate de valores socioambientais e na socialização da comunidade escolar. 
Com a implantação da horta, que é considerada como um laboratório vivo, foi possível integrar as demais áreas do conhecimento, de modo interdisciplinar, permitindo a construção de uma consciência sobre o meio ambiente.

Este projeto evidenciou, nitidamente, que o trabalho com a horta proporcionou o desenvolvimento de novas atitudes e práticas que corroboraram para uma sensibilização sobre a preservação do meio ambiente. Isso se deu também pela cooperação, percebida por meio do trabalho em equipe, que auxiliou no desenvolvimento dessas práticas sociais entre crianças da Educação Infantil, desenvolvendo as relações ecológicas a partir de valores sociais.

\section{Referências}

BRASIL. Base Nacional Comum Curricular (BNCC). Educação é a Base. Brasília, MEC/CONSED/UNDIME, 2017. Disponível em: $<$ http://basenacionalcomum.mec.gov.br/images/BNCC_publicacao.pdf>. Acesso em: 29 set. 2018.

BRASIL. Diretrizes Curriculares Nacionais para Educação Infantil. Brasília, 2010.

BRASIL. Parecer no 20 do Conselho Nacional de Educação/Câmara de Educação Básica. Infantil. Brasília, 2009.

Moreira, H., \& Caleffe, L. G. (2008). Metodologia da pesquisa para professor pesquisador. $2^{\mathrm{a}}$ ed. Rio de Janeiro: Lamparina.

OLIVEIRA, Zilma. R (Org). O Trabalho do Professor a Educação Infantil. 1a. Biruta, 2012. São Paulo.

PENTEADO, Heloísa Dupas de Oliveira. Meio ambiente e formação de professores. SP: Cortez, 2003. João Carlos de Oliveira Caminhos de Geografia Uberlândia, v. 10, n. 31 Set/2009.

PIAGET, Jean. A epistemologia genética: sabedoria e ilusões da filosofia; problemas de psicologia genética. Trad. Nathanael C. caixeiro; Zilda A. Daeir e Célia E. A. Di Piero. 2 ed. São Paulo, Abril Cultural, 1983. (Col. Os pensadores)

Rocha, M., \& Aguiar, F. (2003). Pesquisa intervenção e a produção de novas análises. Psicologia: Ciência e Profissão, 4, 64-73. Brasília: CFP.

SOARES, E. C., NAVARRO, M. A. e FERREIRA, A. P., Desenvolvimento sustentado e consciência ambiental: natureza, sociedade e racionalidade Bernardo. Ciências \& Cognição 2004; Vol 02: 42-49.

SORRENTINO, M. et al. Educação Ambiental como política pública. Educação e Pesquisa, São Paulo, v. 31, n. 2, maio-ago. 2005.

TIRIBA, L. Crianças da natureza: Educação Ambiental para sociedades sustentáveis, NIMA/PUC-Rio, 2010. 